\title{
FIRST RESULTS OF THE DESIS IMAGING SPECTROMETER ON BOARD THE INTERNATIONAL SPACE STATION
}

\author{
E. Carmona ${ }^{\mathrm{a}}$, K. Alonso-González ${ }^{\mathrm{a}}$, M. Bachmann ${ }^{\mathrm{a}}$, D. Cerra ${ }^{\mathrm{a}}$, D. Dietrich ${ }^{\mathrm{a}}, \mathrm{U}$ Heiden $^{\mathrm{a}}, \mathrm{U}^{\mathrm{U}}$ Knodt $^{\mathrm{b}}$, \\ D. Krutz ${ }^{\mathrm{c}}$, R. Müller ${ }^{\mathrm{a}}$, R. de los Reyes ${ }^{\mathrm{a}}$, M. Tegler ${ }^{\mathrm{a}}, \mathrm{V}_{\text {. Ziel }}^{\mathrm{a}}$
}

\begin{abstract}
${ }^{\text {a }}$ German Aerospace Center (DLR), Earth Observation Center (EOC), D-82234 Wessling, Germany
${ }^{\mathrm{b}}$ German Aerospace Center (DLR), Strategie und Vernetzungen, Linder Höhe, 51147 Köln, Germany

${ }^{\mathrm{c}}$ German Aerospace Center (DLR), Optical Sensor Systems (OS), Rutherfordstraße 2, 12489 Berlin, Germany
\end{abstract}

\section{INTRODUCTION}

DESIS (DLR Earth Sensing Imaging Spectrometer) is a space-based hyperspectral sensor currently installed and operated in the International Space Station (ISS). The instrument is the result of the collaboration between the German Aerospace Center (DLR) and Teledyne Brown Engineering (TBE). DLR has developed the instrument and the software for data processing, while TBE provides the Multi-User System for Earth Sensing (MUSES), where DESIS is installed, and the infrastructure for operation.

After finishing the commissioning phase, DESIS data will be available to TBE commercial customers as well as DLR scientific users and collaborators. We present here an overview of the DESIS instrument and processing chain and the first results obtained during the commissioning phase of the instrument.

\section{DESIS INSTRUMENT}

DESIS is installed in one of the 4 slots of the MUSES platform [1]. MUSES is connected to the EXPRESS Logistics Carriers (ELC-4) in the ISS and it provides power, communication, attitude and position data to the accommodated instruments. MUSES also offers pointing capabilities with a gimbal system that supports $\pm 25^{\circ}$ forward/backward and $45^{\circ}$ backboard and $5^{\circ}$ starboard view angles.

DESIS is a pushbroom hyperspectral instrument in the VNIR range $(400-1000 \mathrm{~nm})$ that offers very narrow $(2.55$ $\mathrm{nm}$ ) spectral sampling capabilities [2]. The swath width of DESIS is $30 \mathrm{~km}$ and the spatial resolution is $30 \mathrm{~m}$. Other main parameters of the DESIS instrument are summarized in Table 1. DESIS is also equipped with an on-board calibration unit and a rotating pointing mirror (POI). The POI can change the line of sight $\pm 15^{\circ}$ in the forward/backward direction (independently of the MUSES orientation) allowing BRDF measurements of the same ground area.

\begin{tabular}{|l|l|}
\hline Parameter & \\
\hline F\# & 2.8 \\
\hline Focal length & $320 \mathrm{~mm}$ \\
\hline FoV & $4.1^{\circ}$ \\
\hline IFoV & $0.004^{\circ}$ \\
\hline GSD & $30 \mathrm{~m}$ \\
\hline Spatial pixels & 1024 \\
\hline Swath & $30 \mathrm{~km}$ \\
\hline Spectral range & $400 \mathrm{~nm}-1000 \mathrm{~nm}$ \\
\hline Spectral channels & $235(\mathrm{no}$ binning) \\
\hline Spectral sampling & $2.55 \mathrm{~nm}$ \\
\hline Spec. binning modes & no, $2,3,4$ \\
\hline $\begin{array}{l}\text { SNR (albedo } \\
\text { 550nm) }\end{array}$ & $195(\mathrm{no}$ binning) \\
\hline Radio. Linearity & $386(\mathrm{binning} 4)$ \\
\hline Radio. Resolution & $>95(10 \%-90 \% \mathrm{FWC})$ \\
\hline MTF at Nyquist & $2 \mathrm{gains} \mathrm{with} 13 \mathrm{bit}$ \\
\hline FWHM & $>20^{\circ} \%$ \\
\hline Max. frame rate & $\sim 3.5 \mathrm{~nm}$ \\
\hline $\begin{array}{l}\text { Pointing (forward / } \\
\text { backward POI) }\end{array}$ & $\pm 15^{\circ}$ \\
\hline $\begin{array}{l}\text { Pointing accuracy of } \\
\text { MUSES }\end{array}$ & $0.008^{\circ}$ \\
\hline $\begin{array}{l}\text { Pointing knowledge of } \\
\text { MUSES }\end{array}$ & $<0.004^{\circ}$ \\
\hline Mass & $88 \mathrm{~kg}$ \\
\hline
\end{tabular}

Table 1 Parameters of the DESIS instrument.

\section{DESIS DATA PROCESSING CHAIN}

The DESIS automatic data processing chain [3] provides different level products from the imaging DESIS data. Following the European Space Agency definition, the DESIS level products are Level 0 (L0), Level 1A (L1A), 
Level 1B (L1B) and Level 1C (L1C) and Level 2A (L2A). All products are based on $30 \times 30 \mathrm{~km}$ tiles obtained from the original $30 \mathrm{~km}$ width acquisition stripes.

L1A products are internal (no user deliverable) products consisting of the original raw DESIS data divided into the $30 \times 30 \mathrm{~km}$ tiles where radiometric, spectral and geometric correction and calibration are appended, but not applied. The data include satellite position and pointing annotations. Additional useful information for long term archiving of the L1A products is also derived, including screening of DESIS instrument parameters and evaluation of Dark Current (DC) measurements.

L1B products are L1A data that have been radiometrically calibrated (at-sensor or TOA radiance), spectrally referenced and quality-controlled. Radiometric calibration is performed using calibration tables for the acquisition time period. Systematic sensor effects are also corrected at this step. The corrections applied include dead pixel flagging and interpolation, smile correction and rolling shutter correction. Data quality indicators are generated in L1B products and they include abnormal pixel masks, bandto-band correlations, bad-line and bad-column mask. The L1B products include all information required for further processing the output to higher product levels.

L1C products are L1B products, TOA radiance, orthorectified and resampled to a user selectable map projection. L1C processor employs the technique of rigorous model of the Direct Georeferencing [4]. This technique is based on the line-of-sight (LoS) model, derived from the collinearity equation. To achieve a higher geometric accuracy, an improvement of the (LoS) model is performed by automatic extraction of ground control points (GCP) from reference images with an absolute geometric accuracy of about $15 \mathrm{~m}$ (linear Root Mean Square) using image matching techniques. The L1C products also include quality information about the image matching and orthorectification processes.

L2A products are atmospherically corrected products obtained from the corresponding L1C products. Atmospheric correction is performed with a new code (PACO) which is based on the well-known ATCOR code [5][6]. Over land, and provided that a geometric absolute accuracy better than one pixel is achieved, a combined atmospheric and topographic processing is performed inside PACO. The output L2A products include not only the ground reflectance cube but also maps for estimated water vapor (WV), aerosol optical thickness (AOT) and image masks for land, water, haze, clouds, cloud-shadows and snow.

\section{FIRST DESIS RESULTS}

The DESIS instrument has been in operation since its installation on 28th August 2018. In this time DESIS has operated within the nominal parameters and has acquired more than 1300 products.

Examples of image quicklooks from the L2A products obtained with the DESIS processing chain are shown in Figure 1.
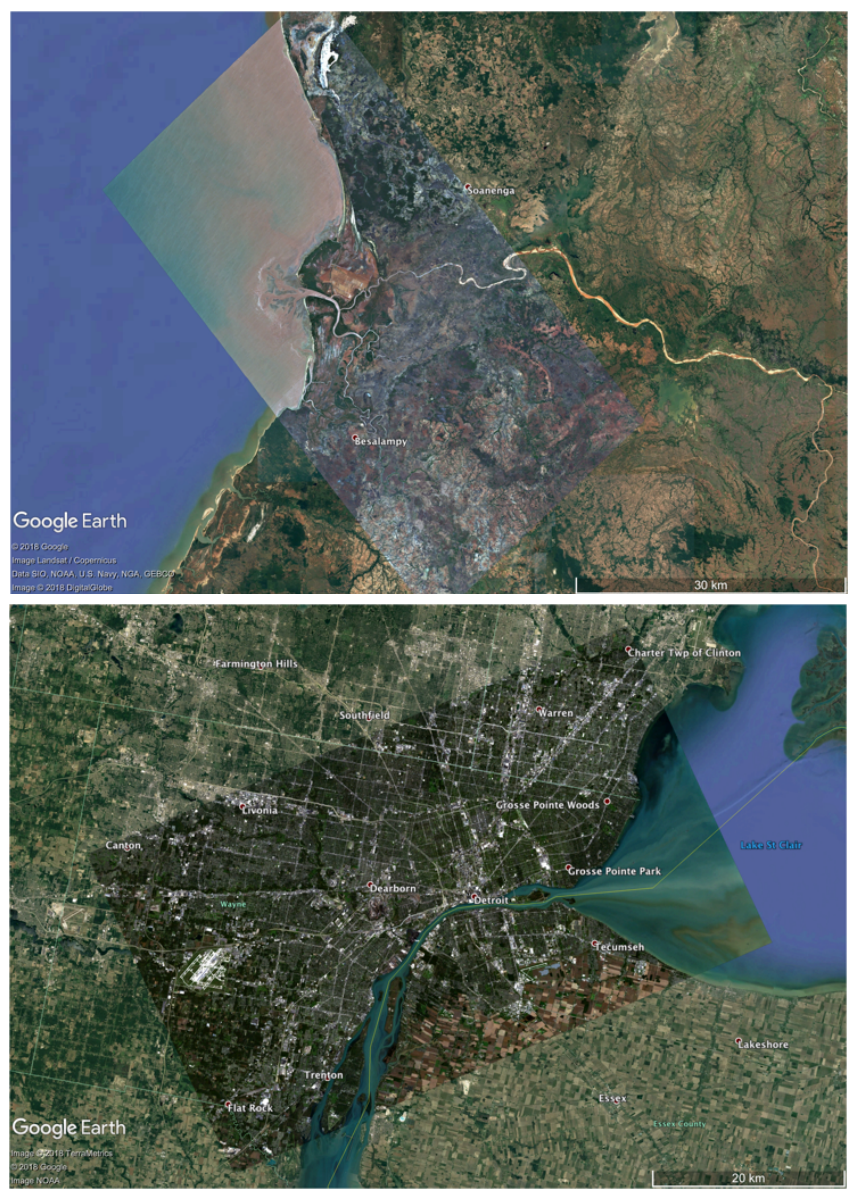

Figure 1 DESIS L2A product quicklooks (highlighted squares of $30 \times 30 \mathrm{~km}^{2}$ in the center) overlapped on Google Earth $\mathbb{C}$. Image on top is taken over the west coast of Madagascar (2 DESIS products shown) while the bottom image (2 DESIS products shown) is taken over Detroit (USA). Quicklooks are generated using the $464 \mathrm{~nm}(B), 553 \mathrm{~nm}(\mathrm{G})$ and $640 \mathrm{~nm}$ (R) bands. 


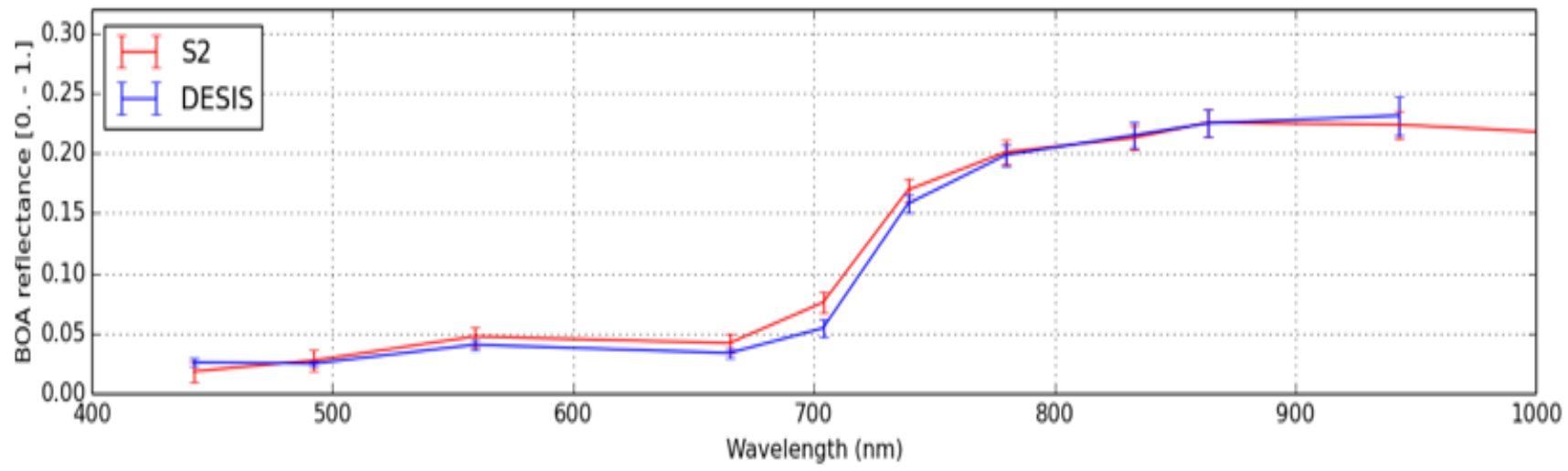

Figure 2 Comparison of S2 and DESIS average reflectance for selected DESIS scene patches. DESIS data have been resampled to match $\mathrm{S} 2$ bands.

Although ISS orbit does not allow for sun-synchronous Earth observations, DESIS instrument has operated with stable temperatures in all monitored components. It has also shown very stable DC values for all image pixels in all imaging conditions. Based on the analysis of the $762 \mathrm{~nm}$ Oxygen band, it has been determined that spectral calibration of the DESIS instrument has also been very stable over time. In addition, the analysis of this spectral feature has been used to asses that no residual smile effect is present after correction in L1B processor.

Concerning geometry, an estimation of boresight angles based on 6489 GCPs shows an accuracy (RMS) of $20 \mathrm{~m}$ in the North-South direction and also $20 \mathrm{~m}$ in the East-West direction, both below 1 pixel $(30 \mathrm{~m})$. The geometry accuracy is reached with DESIS is shown in Figure 1 when overlaying DESIS products over Google Earth (C) maps.

For L2A products, a comparison with Sentinel-II (S2) data has been performed by resampling DESIS reflectance spectra to S2 bands and by selecting scenes less than 5 days apart between DESIS and S2. Results show a good agreement between S2 and DESIS average reflectance as shown in Figure 2 for selected scenes (scenes where conditions for atmospheric correction are applicable). For individual scenes, and patches within the scenes, the absolute differences in reflectance between S2 and DESIS are always below 0.025 for $0 \leq \rho \leq 0.15$ and below 0.030 for $0.15 \leq \rho \leq 0.25$.

A good agreement for $\mathrm{WV}$ and AOT retrieval is also observed in selected L2A products. Agreement between estimated AOT and AERONET stations is better than 0.07 when sufficient dark dense vegetation (DDV) pixels are found in the scene. For WV, the agreement with AERONET stations is typically below $10 \%$ for stations near the area of study.

In addition to reflectance, $\mathrm{WV}$ and AOT, a first assessment of the L2A masks has been carried out during the DESIS commissioning. As an example Figure 3 shows two of the masks which are produced as part of the L2A product (cloud mask and shadow-cloud mask).

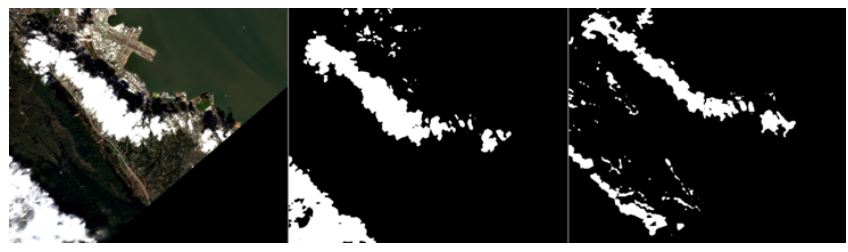

Figure 3 L2A quicklook image (left) and corresponding cloud mask (center) and cloud shadow mask (right).

\section{BIBLIOGRAPHY}

[1] Perkins, R., e. al., "Teledynes multi-user system for earth sensing (muses)," JACIE (Joint Agency Commercial Imagery Evaluation) Workshop, 2016

[2] D. Krutz, I. Sebastian, A. Eckardt et al., DESIS - DLR earth sensing imaging spectrometer for the International Space Station ISS. Proc. SPIE 10785, Sensors, Systems, and Next-Generation Satellites XXII, 107850K; doi: 10.1117/12.2325644. 2018 .

[3] Müller, R., Avbelj, J., Carmona, E., Eckardt, A., et al., The new hyperspectral sensor desis on the multi-payload platform muses installed on the ISS. International Archives of the Photogrammetry, Remote Sensing \& Spatial Information Sciences 41. 2016.

[4] Müller, R., Krauß, T., Schneider, M., Reinartz, P., Automated Georeferencing of Optical Satellite Data with Integrated Sensor Model Improvement. Photogrammetric Engineering and Remote Sensing (PE\&RS), 78 (1), Pages 61- 74. American Society for Photogrammetry and Remote Sensing. ISSN 0099-1112. 2012. 
[5] Richter, R., A spatially adaptive fast atmospheric correction algorithm. International Journal of Remote Sensing, 17(6), pp. 1201-1214. 1996

[6] Richter, R., Atmospheric Correction Methods for Optical Remote Sensing Imagery of Land. In: Advances in Environmental Remote Sensing Remote Sensing Applications. Taylor \& Francis, London. Seiten 161-172. ISBN 978-1-4200- 9175-5. 2011. 